Article

\title{
Comparison of Atmospheric Circulation Anomalies between Dry and Wet Extreme High-Temperature Days in the Middle and Lower Reaches of the Yellow River
}

\author{
Hangcheng Ge ${ }^{1}$, Gang Zeng ${ }^{1, *(\mathbb{D}}$, Vedaste Iyakaremye ${ }^{1} \mathbb{D}$, Xiaoye Yang $^{1}$ and Zongming Wang ${ }^{2}$ \\ 1 Key Laboratory of Meteorological Disaster of Ministry of Education (KLME), Collaborative Innovation Center \\ on Forecast and Evaluation of Meteorological Disasters (CIC-FEMD), Nanjing University of Information \\ Science and Technology, Nanjing 210044, China; gehangcheng@nuist.edu.cn (H.G.); vedastei@yahoo.fr (V.I.); \\ yangxiaoye@nuist.edu.cn (X.Y.) \\ 2 Henan Meteorological Service Center, Zhengzhou 450003, China; zzwzms@163.com \\ * Correspondence: zenggang@nuist.edu.cn
}

check for

updates

Citation: Ge, H.; Zeng, G.; Iyakaremye, V.; Yang, X.; Wang, Z. Comparison of Atmospheric

Circulation Anomalies between Dry and Wet Extreme High-Temperature Days in the Middle and Lower Reaches of the Yellow River. Atmosphere 2021, 12, 1265. https:// doi.org/10.3390/atmos12101265

Academic Editor: Dae Il Jeong

Received: 28 August 2021

Accepted: 22 September 2021

Published: 28 September 2021

Publisher's Note: MDPI stays neutral with regard to jurisdictional claims in published maps and institutional affiliations.

Copyright: (c) 2021 by the authors. Licensee MDPI, Basel, Switzerland. This article is an open access article distributed under the terms and conditions of the Creative Commons Attribution (CC BY) license (https:/ / creativecommons.org/licenses/by/ $4.0 /)$.

\begin{abstract}
Many previous studies have reported that atmospheric circulation anomalies are generally the direct cause of extreme high-temperature (EHT). However, the atmospheric circulation anomalies of EHT days with different humidity and the differences between them are less often discussed, while humidity plays an important role in how people feel in a high-temperature environment. Therefore, this study uses 1961-2016 CN05.1 daily observational data and NCEP/NCAR reanalysis data to classify summer EHT days in China into dry and wet. Furthermore, we investigate the atmospheric circulation anomalies associated with the dry and wet EHT days in the middle and lower reaches of the Yellow River (MLRYR). The results reveal that dry EHT days are likely to be caused by adiabatic heating from anomalous subsidence, while wet EHT days are more likely caused by the low-latitude water vapor and heat anomalies brought by the Western Pacific Subtropical High (WPSH). This may be due to a remarkable westward/southward/narrowed extension of the Continental High $(\mathrm{CH}) / \mathrm{WPSH} /$ South Asian High (SAH) accompanied by an occurrence of dry EHT day. The opposite pattern is observed for wet EHT days. Moreover, a wave train like the Silk Road pattern from the midlatitudes could affect the dry EHT days, while wet EHT days are more likely to be affected by a wave train from high latitudes. Knowing the specific characteristics of dry and wet EHT days and their associated atmospheric circulations could offer new insights into disaster risk prevention and reduction.
\end{abstract}

Keywords: extreme high temperature; the middle and lower reaches of the Yellow River; atmospheric circulation anomaly

\section{Introduction}

Due to global warming, extreme high-temperature (EHT) events have become more frequent and have had more disastrous impacts on public health and the socio-economic system [1-4]. For example, the 2003 summer EHT in Europe resulted in more than 20,000 deaths, and the economic loss was estimated to exceed 13 billion euros [5]. In China, heatwave-related mortality has risen by a factor of four from 1990 to 2019, reaching 26,800 deaths in 2019 [6]. Furthermore, a recent study [7] indicated that if the global temperature continues to rise, China's urban agglomerations are likely to experience an increase of 3-13 heat danger days in the near future (2041-2060) compared to in recent period (1995-2014). Moreover, the influence of anthropogenic activities is detectable in the frequency of EHT days over China, and it is expected that the frequency and intensity of EHT days may increase in the future [8-10].

In recent years, studies on change in EHT have attracted the attention of government officials and scientific communities. Researchers indicated that EHT over China witnessed an 
insignificant trend from the 1960s to the 1980s, while an increasing trend was observed from the 1990s onwards. However, the change varies slightly from one region to another [11-14]. Many studies indicated that EHT days in China are mainly due to the Western Pacific Subtropical High (WPSH), South Asian High (SAH), subtropical westerly jet in East Asia, Pacific-Japan (PJ), and Eurasia-Pacific (EUP) teleconnection patterns [15-18].

Many previous studies [11-18] have discussed EHT based only on temperature. However, human thermal sensation depends not only on temperature but also on relative humidity. The difference in humidity brings completely different thermal sensations to the human body, even at the same temperature. When the temperature is high and the humidity is low, the human body can effectively dissipate heat, while if the humidity is also high, it may cause heatstroke or even death [19-21].

A few studies [22-26] investigated the changes in wet EHT in China and their causes. Tan [22] indicated that when the environment is hot, the increase in air humidity will significantly increase the thermal sensation of the human body. Tian et al. [23] showed that when the ambient air temperature is greater than $28^{\circ} \mathrm{C}$ and the Relative Humidity $(\mathrm{RH})$ is greater than $70 \%$, the relative air humidity significantly impacts the thermal feeling and thermal comfort. When the RH reaches $90 \%$, its influence is much more significant than $70 \%$ and $80 \%$. Various techniques have been employed to categorize EHT into dry and wet. Ding et al. [24] classified the dry and wet heat events with the heat index from the United States (US) National Weather Service (NWS) and counted the severe dry and wet events under different conditions, and then investigated their interannual variability. Chen et al. [25] used 850-hPa specific humidity to differentiate dry and wet EHT events at Beijing station between July and August 1979-2008. Xu et al. [26] investigated the spatial and temporal changes of dry and humid heat waves (HWs) in China based on the heat index, and found that the humid HWs in China occur 20\% more frequently than dry HWs. The largest increment of dry and humid HW frequency appears in the northwest and southeast China respectively. In estimating projected changes in high-temperature conditions, numerous studies show that if humidity is taken into account, the global heatwave-related disasters at the end of this century will be higher than in the recent past; heatwaves may increase by 5 to 10 times [27-30]. Although numerous studies on dry and wet EHT days have been carried out in China, those were limited to a single site and mainly focused on the impacts of dry and wet EHT days on the human body's comfort [31-33]. Less attention was paid to their associated atmospheric circulation anomalies and physical mechanisms, which may affect EHT prediction accuracy.

Therefore, the present study aims first to find a significant area of overlapping dry and wet EHT days in China and then compare the atmospheric circulation difference between the dry and wet EHT days in this area, which will be crucial to understand the origins of dry and wet EHT days. The rest of this study is organized as follows. First, Section 2 describes the data and methods. Then, in Section 3, atmospheric circulation anomalies of two types of high temperatures are elaborated. Finally, the conclusions are presented in the Section 4.

\section{Data and Methods}

\subsection{Data}

The daily CN05.1 maximum temperature and relative humidity gridded datasets from the National Climate Center of China were used in the present study. This data comprises of high-quality controlled in-situ datasets interpolated into $1.0^{\circ} \times 1.0^{\circ}$ resolution [34]. In addition, the daily atmospheric circulation fields were retrieved from the National Centers for Environmental Prediction-National Center for Atmospheric Research (NCEP-NCAR) Reanalysis I datasets with a $2.5^{\circ} \times 2.5^{\circ}$ horizontal resolution from 1961 to 2016, including the zonal and meridional winds, geopotential height, and specific humidity in pressure levels from $100 \mathrm{hPa}$ to $1000 \mathrm{hPa}$, air temperature and relative humidity from $300 \mathrm{hPa}$ to $1000 \mathrm{hPa}$ [35]. This dataset was used to analyze the atmospheric circulation in and around Asia. The summer is from June to August in this study. 


\subsection{Methods}

\subsubsection{Definition of Dry and Wet EHT Days}

This study adopted a heat index (HI) from the US National Weather Service (NWS). The same HI definition has been used in the previous study [36] to identify dry and wet EHT days. The present study uses the same definition as described in Equation (1) to calculate the $\mathrm{HI}$ using the $\mathrm{CN} 05.1$ maximum temperature and relative humidity data.

$$
\begin{gathered}
\mathrm{HI}=-42.379+2.04901523 * \mathrm{~T}+10.14333127 * \mathrm{RH}-0.22475541 \\
* \mathrm{~T} * \mathrm{RH}-0.00683783 * \mathrm{~T} * \mathrm{~T}-0.05481717 * \mathrm{RH} * \mathrm{RH}+0.00122874 * \mathrm{~T} \\
* \mathrm{~T} * \mathrm{RH}+0.00085282 * \mathrm{~T} * \mathrm{RH} * \mathrm{RH}-0.00000199 * \mathrm{~T} * \mathrm{~T} * \mathrm{RH} * \mathrm{RH}
\end{gathered}
$$

where $\mathrm{T}$ and RH denote temperature in degrees Fahrenheit and relative humidity $(\mathrm{RH})$ in percent.

If the $\mathrm{RH}$ is less than $13 \%$ and the temperature is between 80 and $112{ }^{\circ} \mathrm{F}(26.7$ and $44.4^{\circ} \mathrm{C}$ ), the following adjustment (Equation (2)) is subtracted from HI. On the other hand, if the $\mathrm{RH}$ is greater than $85 \%$ and the temperature is between 80 and $87^{\circ} \mathrm{F}\left(26.7\right.$ and $\left.30.6^{\circ} \mathrm{C}\right)$, the following adjustment (Equation (3)) is added.

$$
\begin{gathered}
\text { ADJUSTMENT }=\frac{13-\mathrm{RH}}{4} * \sqrt{\frac{17-|\mathrm{T}-95|}{17}} \\
\text { ADJUSTMENT }=\frac{\mathrm{RH}-85}{10} * \frac{87-\mathrm{T}}{5}
\end{gathered}
$$

Note that when the heat index value is below $80^{\circ} \mathrm{F}\left(26.7^{\circ} \mathrm{C}\right)$, the calculation of $\mathrm{HI}$ needs to be used the following simpler formula:

$$
\mathrm{HI}=0.5 *[\mathrm{~T}+61.0+(\mathrm{T}-68.0) * 1.2+(\mathrm{RH} * 0.094)]
$$

\begin{tabular}{|c|c|}
\hline Heat Index & Description \\
\hline $80-90^{\circ} \mathrm{F}\left(26.7-32.2^{\circ} \mathrm{C}\right)$ & $\begin{array}{l}\text { Caution: Fatigue is possible with prolonged exposure and/or } \\
\text { physical activity. }\end{array}$ \\
\hline $90-103^{\circ} \mathrm{F}\left(32.2-39.4^{\circ} \mathrm{C}\right)$ & $\begin{array}{l}\text { Extreme caution: Sunstroke, muscle cramps, and/or heat } \\
\text { exhaustion possible with prolonged exposure and/or physical } \\
\text { activity. }\end{array}$ \\
\hline $103-125^{\circ} \mathrm{F}\left(39.4-51.6^{\circ} \mathrm{C}\right)$ & $\begin{array}{l}\text { Danger: Sunstroke, muscle cramps, and/or heat exhaustion likely. } \\
\text { Heatstroke is possible with prolonged exposure and/or physical } \\
\text { activity. }\end{array}$ \\
\hline$>125^{\circ} \mathrm{F}\left(51.6^{\circ} \mathrm{C}\right)$ & Extreme danger: heat stroke likely. \\
\hline
\end{tabular}

Different levels of heat index of health risks are described in Table 1 which is provided by NWS.

Table 1. Different levels of a heat index of health risks.

According to Table 1, it can be found that the risk of heat exhaustion and even heat stroke will likely occur if the $\mathrm{HI}$ is greater than $90^{\circ} \mathrm{F}\left(32.2^{\circ} \mathrm{C}\right)$, indicating the weather is likely an EHT day. Thus, the RH needs to be considered an important factor in identifying of wet and dry EHT. According to previous studies [37,38], when the temperature is higher than $30^{\circ} \mathrm{C}$ and humidity higher than $84-85 \%$, it is not easy to regulate body temperature and heatstroke can easily happen. While conditions below $60 \%$ humidity are not considered as wet environment [39], and thermal discomfort is limited [40]. Therefore, it can be seen from the above research that it is reasonable to select $60 \%$ and $85 \%$ as the relative humidity threshold of dry and wet EHT, respectively.

Therefore, the wet EHT day is defined when weather with HI greater than $90^{\circ} \mathrm{F}$ and relative humidity greater than $85 \%$ occur; weather with $\mathrm{HI}$ greater than $90^{\circ} \mathrm{F}$ and relative humidity less than $60 \%$ is defined as dry EHT day. We counted the number of days with dry and wet EHT for each grid point across China and identified a region with overlapping 
dry and wet EHT days and retained all the days with $1 / 3$ of the region satisfying dry or wet EHT days.

\subsubsection{Wave Activity Flux}

The wave activity flux (WAF) will be calculated to describe the propagation of Rossby waves in the Eurasian region. The formulation of the two-dimensional wave activity flux by Plumb [41] is expressed as:

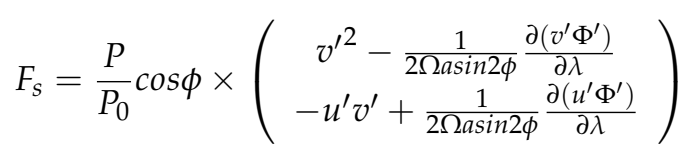

where $\Phi$ denotes the geopotential, $\Omega$ the Earth's rotation rate, $P$ the air pressure, $P_{0}$ the value of $1000 \mathrm{hPa}, u$ and $v$ are the zonal and meridional wind, respectively, $\phi$ the latitude, $\lambda$ the longitude, and $a$ the radius of the Earth. The superscript / indicates a partial derivative.

\subsubsection{Identification of Some High-Pressure Systems}

The pattern differences of well-known High-pressure systems between dry and wet EHTs are investigated in this study. These systems include SAH represented by the 12,500 geopotential meter (gpm) isoline at $200 \mathrm{hPa}$. WPSH is represented by the $5860 \mathrm{gpm}$ isoline at $500 \mathrm{hPa}$. We take the northern boundary index of the WPSH as the latitude location of the WPSH in this study, i.e., the average latitude of northern grids intercrossed by the $5860 \mathrm{gpm}$ isoline at $500 \mathrm{hPa}$ and longitudes within the region $\left(0^{\circ}-60^{\circ} \mathrm{N}, 80^{\circ}-160^{\circ} \mathrm{E}\right)$. And referring to the definition of $\mathrm{CH}$ in Tan et al. [42], it will be identified as a $\mathrm{CH}$ when an obvious anticyclone at $500 \mathrm{hPa}$ appears in the area $\left(32.5^{\circ}-55^{\circ} \mathrm{N}, 80^{\circ}-140^{\circ} \mathrm{E}\right)$ and the longitude difference of distance between the north and south of this anticyclone is greater than 7.5 latitudes. Then, the average longitude of the anticyclone is computed as the zonal location of this $\mathrm{CH}$.

\section{Results and Discussion}

The dry and wet EHT days in China from 1961 to 2016 are shown in Figure 1. It can be found that the dry EHT days mostly occurred in northern China, especially in northwest China, while the wet EHT days mostly occurred in southeast China, which is consistent with the results of a previous study [24]. The overlapping area between the dry and wet EHT days is from the middle-lower valley of the Yangtze River to the eastern part of northeast China, with a large value center in the middle-lower reaches of the Yellow River (MLRYR). Therefore, we take the area $\left(32.5^{\circ}-40^{\circ} \mathrm{N}, 110^{\circ}-120^{\circ} \mathrm{E}\right)$ as MLRYR that frequently suffers from not only dry EHT days but also the wet EHT days, which poses severe impacts for agriculture, the social-economic system, and public health. The MLRYR region is considered to have a dry (wet) EHT day if more than $1 / 3$ of the grids in this region meet the definition of dry (wet) EHT. This definition reveals 553 dry EHT days and 445 wet EHT days in the study period. Next, continuous dry and wet days are regarded as a single event and the first day of occurrence is defined as the EHT day, including single dry (wet) EHT days. As a result, 192 dry EHT onset days and 222 wet EHT onset days were used to explore the possible mechanisms leading to the formation of dry and wet EHT days. 
(a) Dry EHT

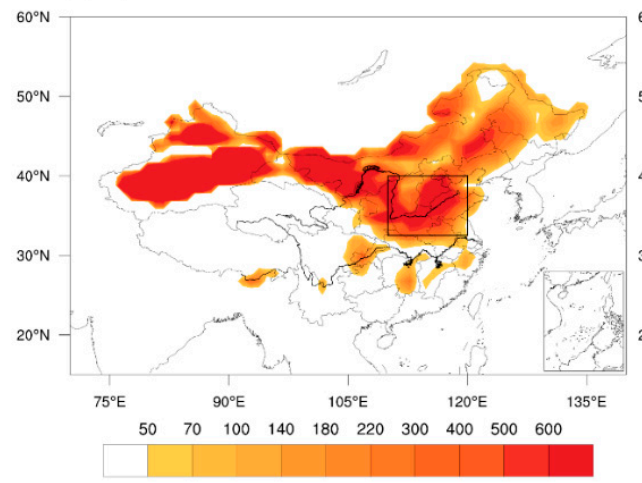

(c) Overlapped area (b) Wet EHT

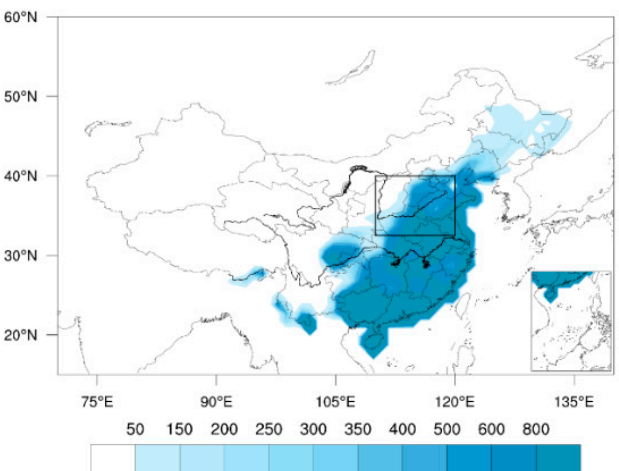

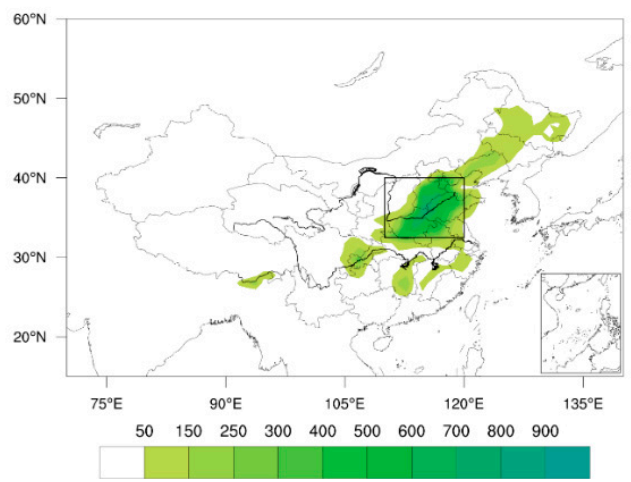

Figure 1. The sum of EHT frequency distribution of dry and wet in China from 1961 to 2016 in summer (June-august) (unit: day). (a) Dry EHT area, (b) wet EHT area, (c) overlapped area. Black box $\left(32.5^{\circ}-45^{\circ} \mathrm{N}, 110^{\circ}-120^{\circ} \mathrm{E}\right)$ indicates the regions of the MLRYR. The value in (c) is the minimum of dry and wet EHT days.

The direct and local cause in the heat index increase of dry and wet EHT days can perhaps be seen from Figures 2 and 3. It can be seen that a rise in temperature near the ground, and low relative humidity for dry EHT days. The relative humidity is not more than $60 \%$ in the whole troposphere, except the lower troposphere of east MLRYR (Figure 2c). The pattern of wet EHT days is quite different from that of dry EHT days. The overall temperature change is much smaller than that found in dry EHT days, and there is even a small drop near the ground with the ascending motion. However, the relative humidity is mostly above $85 \%$ with sufficient water vapor. The noticeable changes occur on EHT onset days, regardless of whether the EHT is related to dry or wet weather. When dry EHT day occurs, the strong downward motion of air, resulting from the converged air with a negative GPH anomaly in the upper troposphere and the diverged air with a positive GPH anomaly in the lower troposphere, appears on day -2 (Figure $3 b$ ) and intensifies on day 0 (Figure 3c). That is to say, the increase in the heat index in dry EHT days is most likely caused by the rise in temperature caused by adiabatic heating from anomalous subsidence, while wet EHT days are more likely to be caused due to the large increase in relative humidity, which could make people feel hot and uncomfortable even if the temperature is not particularly high. Research shows that with the strengthening of people's awareness of high-temperature prevention, the wet EHT days in which the temperature is not too high but the humidity is at a high level are more likely to lead to heatstroke than with simple high temperatures [19]. 


\section{Dry EHT}

(a) day -4

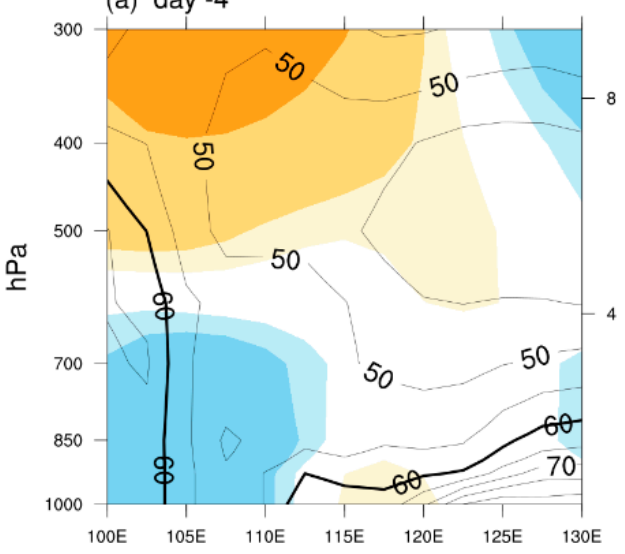

(b) day -2

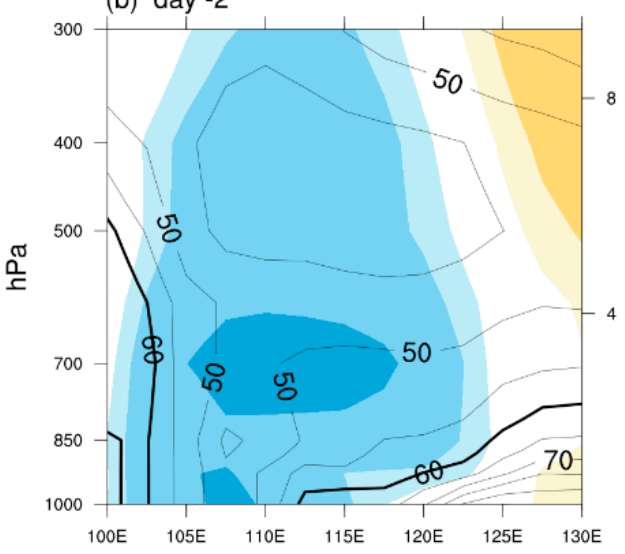

(c) day 0

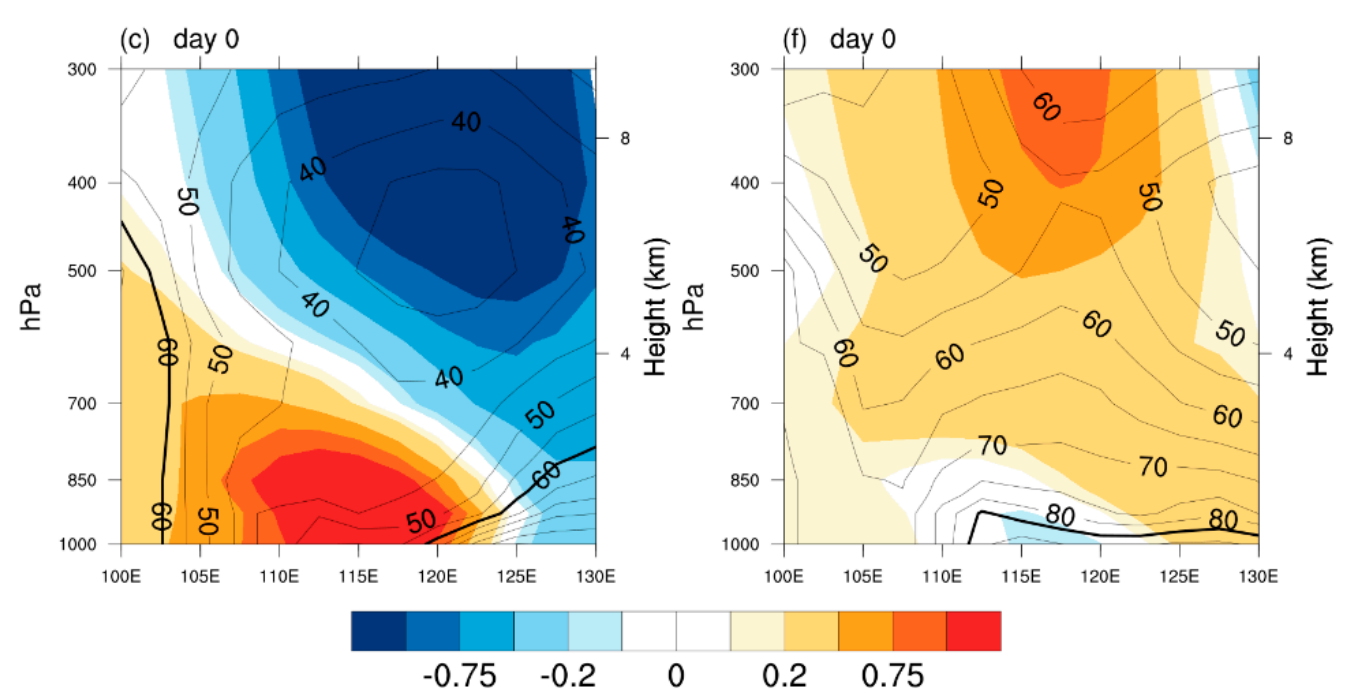

Wet EHT

(d) day -4

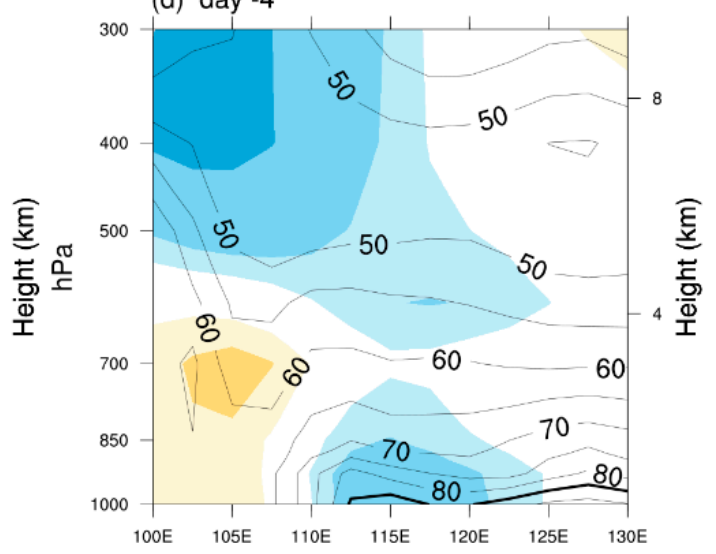

(e) day -2

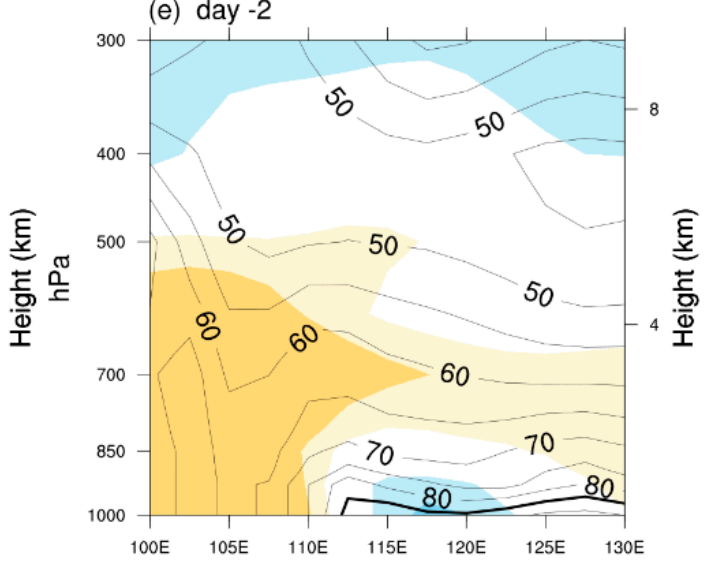

Figure 2. Vertical cross-sections of the average zonal air temperature anomaly (colors; unit: K) and relative humidity (isopleth) from $32.5^{\circ}$ to $40^{\circ} \mathrm{N}$ on dry EHT and wet EHT days in the MLRYR (from day -4 to day $0(\mathbf{a}-\mathbf{c})$ : dry EHT onset days, $(\mathbf{d}-\mathbf{f})$ : wet EHT onset days). 


\section{Dry EHT}

Wet EHT
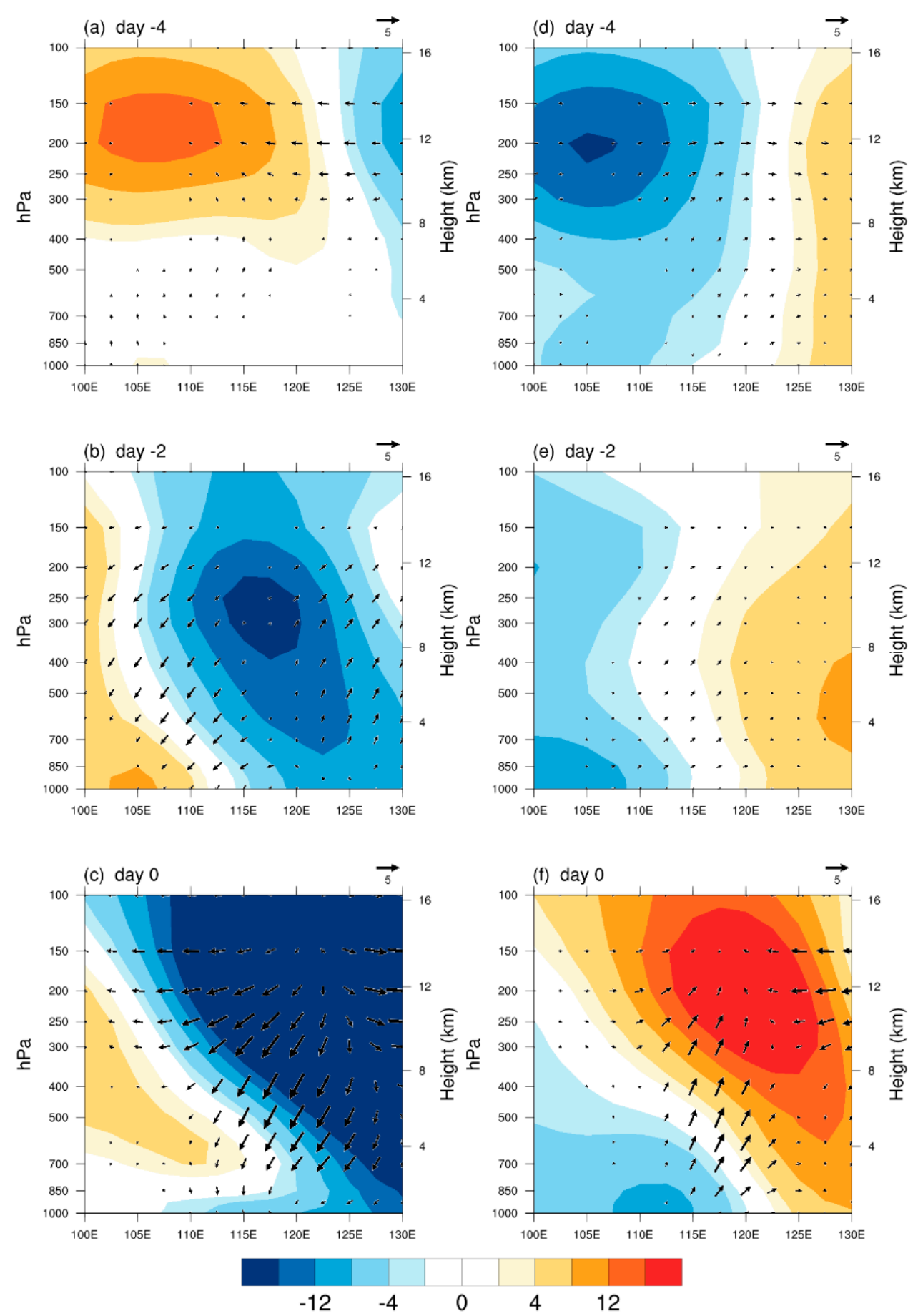

Figure 3. Vertical cross-sections of GPH anomalies (shadings; unit: gpm) and zonal vertical velocity (vector; vertical velocity; unit: pa/s, scale $100 \mathrm{pa} / \mathrm{s}$; zonal wind; unit: $\mathrm{m} / \mathrm{s}$ ) averaged from $32.5^{\circ}$ to $40^{\circ} \mathrm{N}$ from day -4 to onset day for dry EHT days $(\mathbf{a}-\mathbf{c})$ and wet EHT days $(\mathbf{d}-\mathbf{f})$.

Some studies $[43,44]$ have suggested that water vapor transport and diabatic heating in China are closely related to the location of the WPSH. The times of the two northward jumps of the WPSH correspond well to the position of the main rain belt in eastern China. Thus, northward WPSH can bring more water vapor to northern China. Water vapor can directly affect the relative humidity in the air, so the difference in water vapor is crucial for the two types of EHT. The difference in water vapor between dry EHT and wet EHT days can be seen in Figure 4. There is less water vapor in the MLRYR for dry EHT days. However, 
when a wet EHT day occurs, there is more water vapor, showing a clear convergence of water vapor brought by the south wind, which mainly comes from the western Pacific and the northern Indian Ocean. Thus, this difference in the amount of water vapor may be due to the location difference of the WPSH in dry and wet EHT days.

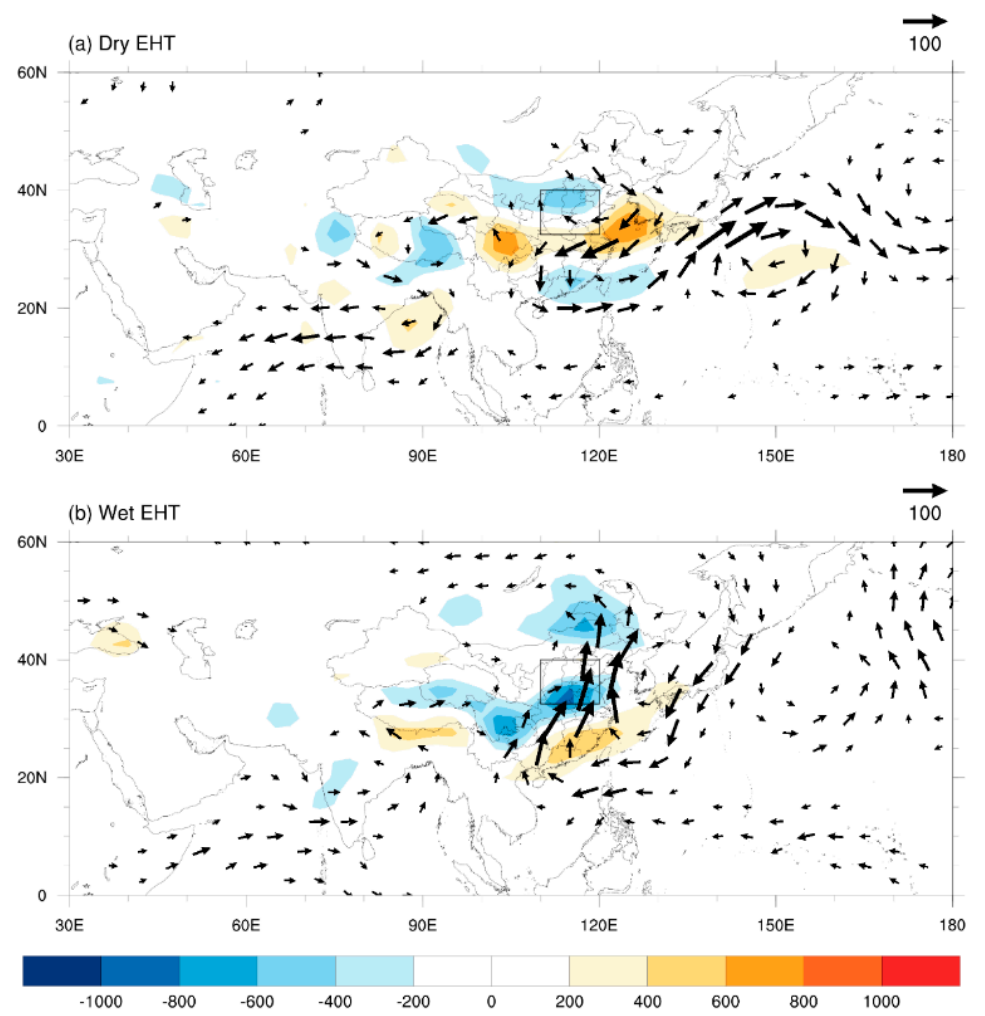

Figure 4. Composite anomalies of the whole layer (from $300 \mathrm{hPa}$ to $1000 \mathrm{hPa}$ ) water vapor flux (vector; unit: $10^{2} \mathrm{~kg} /(\mathrm{m} \cdot \mathrm{s})$ ) and its divergence (shadings; $10^{-5} \mathrm{~kg} /\left(\mathrm{m}^{2} \cdot \mathrm{s}\right)$ ) in (a) dry and (b) wet EHT days in MLRYR.

For EHT in southern China, the Western Pacific Subtropical High (WPSH) and South Asian High (SAH) are the key systems $[9,10,42,45]$. In addition to these high-pressure systems, some atmospheric teleconnection patterns (e.g., the Silk Road pattern teleconnection, East Asia-Pacific teleconnection) are also essential factors for generating EHT [9,46]. To compare the difference of geopotential height (GPH) between the dry and wet EHT days in MLRYR, a composite analysis of GPH was conducted. Figure 5 shows the composite GPH anomalies and the areal averaged WPSH and the SAH corresponding to dry and wet EHT days. The calculations of anomalies in the present study are based on historical averages for the same period. When a dry EHT day occurs (Figure 5a), the middle latitude of the Asian continent presents a ' +-+ ' Rossby wave train with two anticyclonic anomalies over the ocean surface of eastern Japan and Mongolian Plateau and a cyclonic anomaly over northeast Asia, with an eastward shift of this wave train from the upper troposphere to the lower troposphere. For wet EHT days, the pattern was almost the opposite of that seen in dry EHT days. While both types of EHT days showed positive anomalies at $500 \mathrm{hPa}$ over MLRYR, the GPH positive anomalies are more westward in dry EHT days but are more eastward in wet EHT days. This distribution is consistent with Chen and Lu [25], who suggested an anticyclonic anomaly in the west of the key area for dry EHT days. Looking at the location of some key systems, the SAH/WPSH tends to become narrower than normal and has a southward direction during dry EHT days, and it conversely becomes larger and has a northward direction for wet EHT days. 

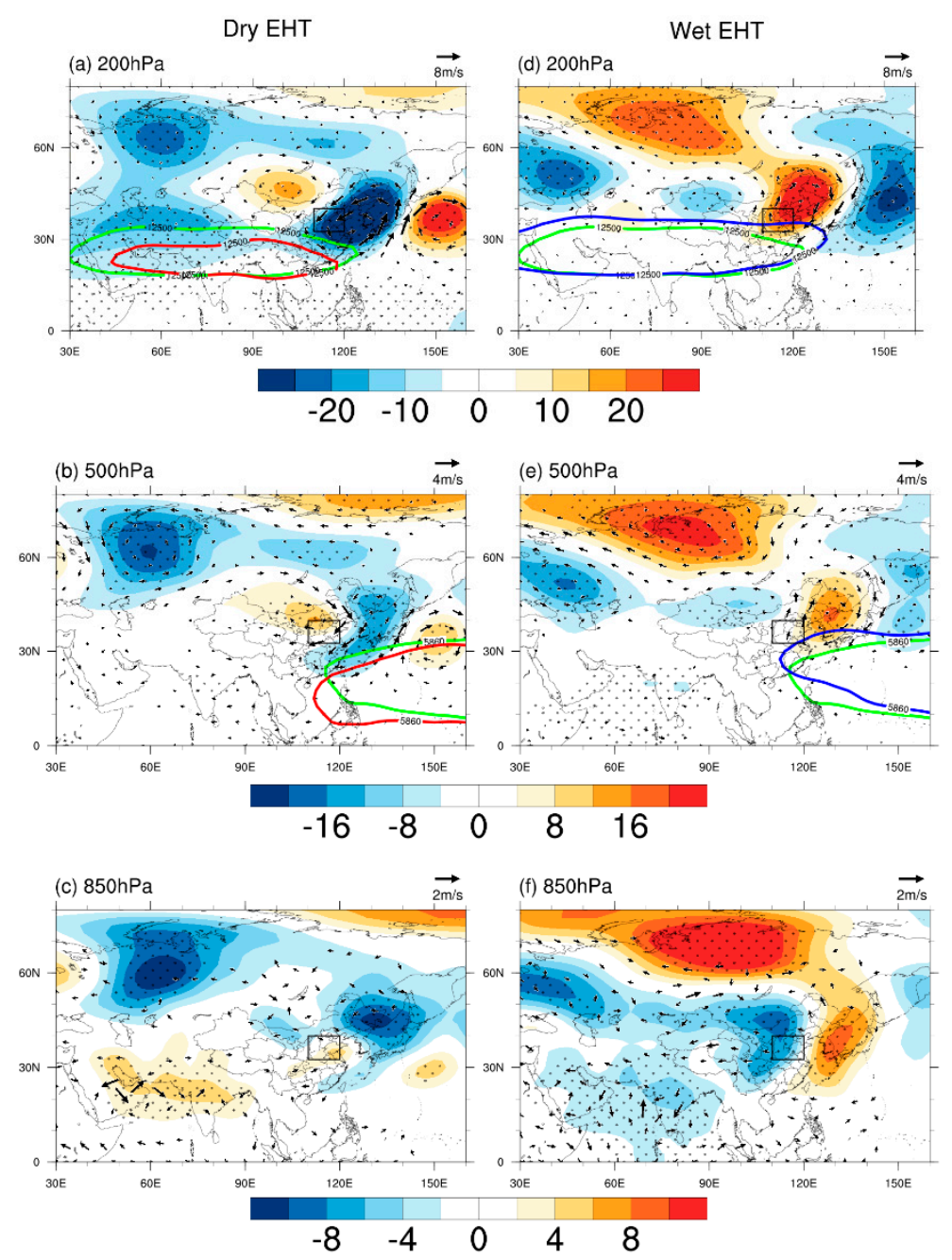

Figure 5. Composite anomalies of GPH (shadings; unit: gpm; dotted areas are significant at the $99 \%$ confidence level) and wind (vector; unit: $\mathrm{m} / \mathrm{s}$ ) for dry and wet EHT days in MLRYR. (a-c): dry EHT, (d-f): wet EHT. The solid green lines are the climatological-mean bodies of SAH at $200 \mathrm{hPa}$ and WPSH at $500 \mathrm{hPa}$, and the red (blue) lines at $200 \mathrm{hPa}$ and $500 \mathrm{hPa}$ are $\mathrm{SAH}$ and WPSH bodies for the dry (wet) EHT days.

Some studies [40] suggested that a positive GPH anomaly south of Lake Baikal in summer may indicate strengthened Continental High $(\mathrm{CH})$, increasing the temperature in northern China.

To investigate the influence of differences in the zonal movement of $\mathrm{CH}$, Table 2 gives the distribution of the zonal location of $\mathrm{CH}$ for dry and wet EHT days. It shows that the presence of the $\mathrm{CH}$ can be detected in more than $60 \%$ of dry or wet EHT days. Considering that $110^{\circ} \mathrm{E}$ is the zonal center of the area $\left(32.5^{\circ}-55^{\circ} \mathrm{N}, 80^{\circ}-140^{\circ} \mathrm{E}\right)$ taken to define $\mathrm{CH}$, and is also the left boundary of the MLRYR, we take $110^{\circ} \mathrm{E}$ as the demarcation line of the zonal location of $\mathrm{CH}$. It can be clearly seen that when dry (wet) EHT day occurs, the $\mathrm{CH}$ is mostly located in the west (east) of $110^{\circ} \mathrm{E}$, with the highest frequency in $90^{\circ}-110^{\circ} \mathrm{E}\left(120^{\circ}-140^{\circ} \mathrm{E}\right)$.

Table 2. Zonal locations distribution of continental high on dry and wet EHT days.

\begin{tabular}{ccccc}
\hline Zonal Location & $\mathbf{8 0}^{\circ} \mathbf{- 9 0 ^ { \circ }} \mathbf{E}$ & $\mathbf{9 0}^{\circ} \mathbf{- 1 1 0 ^ { \circ }} \mathbf{E}$ & $\mathbf{1 1 0}^{\circ} \mathbf{- 1 2 0 ^ { \circ }} \mathbf{E}$ & $\mathbf{1 2 0}^{\circ} \mathbf{- 1 4 0 ^ { \circ }} \mathbf{E}$ \\
\hline Dry EHT & $13.54 \%$ & $30.73 \%$ & $11.46 \%$ & $11.46 \%$ \\
Wet EHT & $8.10 \%$ & $17.57 \%$ & $15.32 \%$ & $31.08 \%$ \\
\hline
\end{tabular}


As mentioned above, the longitudinal position of the WPSH could also influence both dry and wet EHT days in MLRYR. Thus, there is a need to quantify the exact latitude of the WPSH for both dry and wet EHT days. And adiabatic heating from anomalous subsidence under the control of $\mathrm{CH}$ results in a rise of temperature near the ground. Meanwhile, there is less water vapor if WPSH is southward, which leads to low humidity and easy occurrence of dry EHT.

To investigate the influence of the movement of the $\mathrm{CH}$ and WPSH on these two types of EHT days, their scatter diagrams are presented in Figure 6. Considering that $30^{\circ} \mathrm{N}$ is approximately the average latitude of the northern boundary index of the WPSH in summer, we take $30^{\circ} \mathrm{N}$ as the demarcation line of the latitude of the WPSH. The results show that most of the dry EHT days, which account for $54.7 \%$ of dry EHT days, are found in the third quadrant, indicating that they are related to a southward WPSH and a westward $\mathrm{CH}$. Conversely, most wet EHT days, which account for $52.2 \%$ of wet EHT days, are found in the first quadrant, indicating a northward WPSH and an eastward $\mathrm{CH}$. Therefore, the WPSH and $\mathrm{CH}$ locations have an important influence on the two types of EHT days.
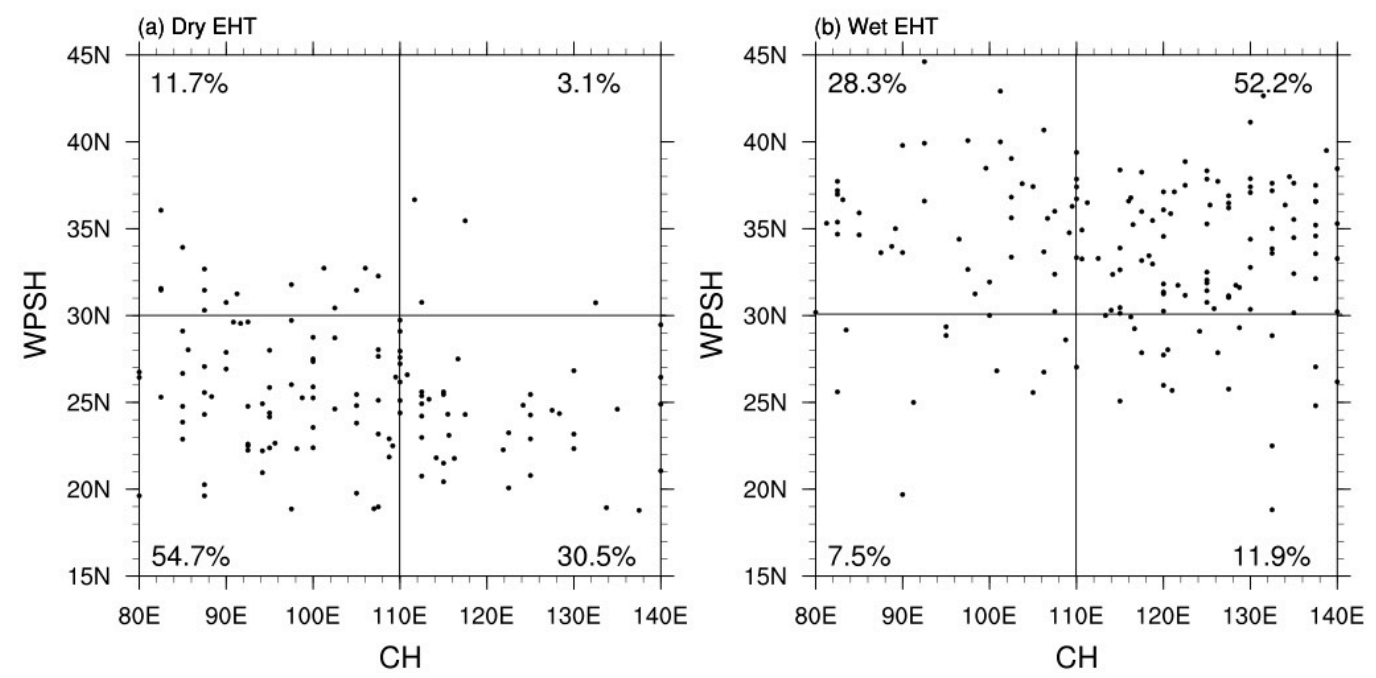

Figure 6. Scatter diagram of the zonal location of $\mathrm{CH}$ and the latitude location of the WPSH for (a) dry and (b) wet EHT days. The percentage in each quadrant is the proportion of EHT days in this quadrant to EHT days in these four quadrants.

Figure 7 shows the evolution of composited $200 \mathrm{hPa}$ GPH and wave activity flux anomalies for dry and wet EHT days. We investigated a larger area to look at teleconnections. It can be found that there exist different atmospheric teleconnections in these two types of EHT days. When a dry EHT day occurs, there is a wave train with a " - + " GPH anomaly pattern over Eurasia, with two negative GPH anomalies located over the eastern Caspian Sea and northeast Asia and a positive center over Xinjiang. This pattern at day -5 to day -4 before the onset is similar to the Silk Road pattern [47] and continues to strengthen until the onset. It reaches its strongest point from day -1 to day 0 with the strongest wave activity flux. The negative center of the GPH anomaly over the eastern Caspian Sea is relatively static, and the wave energy propagates eastward and strengthens the GPH anomaly over MLRYR from day -5 to day 0 , indicating that this negative GPH anomaly seems to be a potential early signal for the occurrence of dry EHT. However, the evolution of wet EHT is different from that of dry EHT. It can be found that the positive GPH anomaly over the east of the MLRYR comes from the positive GPH anomaly over the Sea of Okhotsk and is strengthened. Unlike dry EHT, the wave train for wet EHT mainly comes from a higher latitude and appears as a " -+-+ " pattern with negative GPH anomaly centers located in Europe and northwest China and positive GPH anomaly center located in the southern Novaya Zemlya and northeast China. The negative GPH 
anomaly over Europe seems to be a potential early signal for wet EHT, and wave energy propagates eastward.

Dry EHT
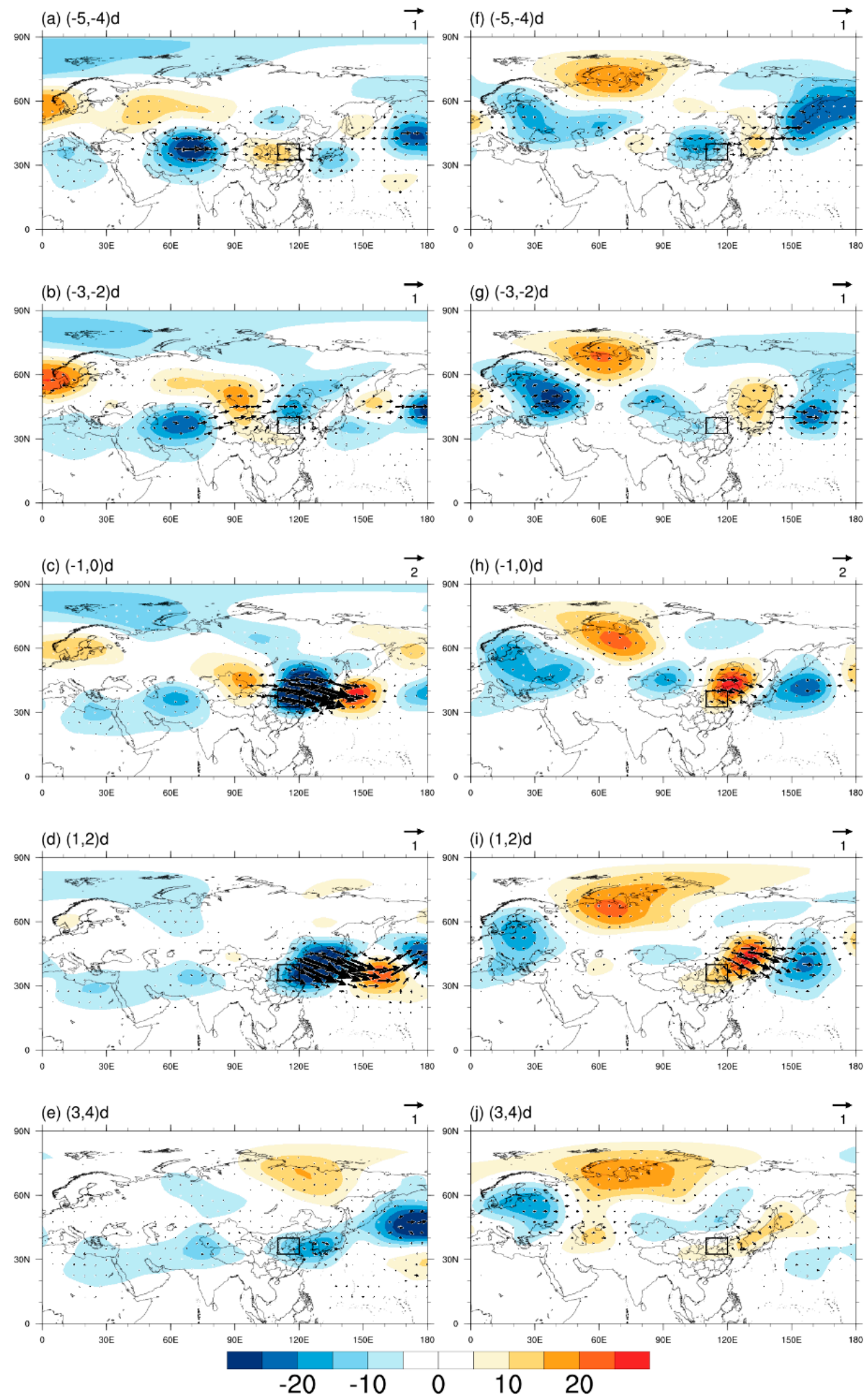

Figure 7. Composite evolution of $200 \mathrm{hPa}$ Plumb wave activity flux (vectors; unit: $\mathrm{m}^{2} / \mathrm{s}^{2}$ ) and geopotential height anomalies (colors; unit: gpm) (from day -5 to day -4 for $(\mathbf{a}-\mathbf{e})$ : dry EHT onset days, $(\mathbf{f}-\mathbf{j})$ : wet EHT onset days). 
Although the present study discusses the difference in atmospheric circulation between dry and wet EHT days in MLRYR, the dynamic and thermodynamic diagnoses for the formation mechanism of these types of EHT days are less investigated and need to be conducted in our future work. We also note that some potential early signals exist for these two types of EHT days, such as negative GPH anomalies over Europe for wet EHT days and over the eastern Caspian Sea for dry EHT days. In addition, a previous study [48] has shown that a concurrent variability of heatwaves existed in northern China and eastern Europe. We should further verify whether these potential early signals can be used to forecast the dry or wet EHT days. The Silk Road pattern [45] is characterized by the GPH anomalies of "+ - + -" (or its opposite) in eastern Europe, central Asia, Mongolia, and the Korean Peninsula-Japan in the upper troposphere over Eurasia, along the axis of the Asian subtropical jet stream (about $40^{\circ} \mathrm{N}$ ), which is close to the position of GPH anomalies for dry EHT days. Therefore, it is worth exploring whether changes in the Silk Road pattern are related to dry EHT. In addition, the interannual and interdecadal variability [49] of dry and wet EHT days in MLRYR and their relationships with forcing factors have been proven to have a significant impact on EHT in China (e.g., sea surface temperature [50,51], sea ice [52], soil moisture [53,54]), and these are also worth exploring in future research.

\section{Conclusions}

Based on CN05.1 observational daily data and NCEP/NCAR reanalysis data from 1961 to 2016, we have classified extreme summer high-temperature (EHT) days in China into dry and wet EHT days. It was found that northwest China and southeast China are dominated by dry and wet EHT days, respectively, with a key overlapping area of these two types of EHT days in the middle and lower reaches of the Yellow River (MLRYR). Dry EHT days could be affected by adiabatic warming from subsidence motion, while wet EHT days are more likely affected by the increased amounts of water vapor brought by the Western Pacific subtropical High (WPSH) from the low-latitude oceans. The atmospheric circulation anomalies of these two types of EHT days in MLRYR are quite different. When a dry EHT occurs, there is a ' +-+ ' Rossby wave train over the middle latitude of the Asian continent, with two anticyclonic anomalies over the ocean surface of eastern Japan and Mongolian Plateau, and a cyclonic anomaly over northeast Asia. However, wet EHT days present an almost opposite pattern to dry EHT days. In addition, the Continental High (CH)/WPSH/South Asian High (SAH) moves more westward/southward/narrowed than normal for dry EHT days, which is the opposite of what happens in the case of wet EHT. The evolution of atmospheric circulation anomalies at synoptic scale suggests that dry EHT is more likely affected by a Rossby wave train from midlatitudes, similar to the Silk Road pattern, while wet EHT is more likely affected by a wave train from high latitudes.

Author Contributions: Formal analysis, H.G. and G.Z.; Writing—original draft, H.G. and G.Z.; Writing-review \& editing, H.G., G.Z., V.I., X.Y. and Z.W. All authors have read and agreed to the published version of the manuscript.

Funding: National Natural Science Foundations of China $(42175035 ; 41831174)$ and National Key Research and Development Program of China (2017YFA0603804).

Acknowledgments: The authors thank the two anonymous reviewers for their very helpful comments and suggestions.

Conflicts of Interest: The authors declare no conflict of interest.

\section{References}

1. Deng, K.; Yang, S.; Liu, A.; Li, C.; Hu, C. Unprecedented East Asian Warming in Spring 2018 Linked to the North Atlantic Tripole SST Mode. Atmos. Ocean. Sci. Lett. 2019, 12, 246-253. [CrossRef]

2. Pi, Y.; Yang, Y.; Zhang, Y.; Xu, C.; Yu, R. Extreme Temperature Events during 1960-2017 in the Arid Region of Northwest China: Spatiotemporal Dynamics and Associated Large-Scale Atmospheric Circulation. Sustainability 2020, 12, 1198. [CrossRef]

3. Yatim, A.N.M.; Latif, M.T.; Ahamad, F.; Khan, M.F.; Nadzir, M.S.M.; Juneng, L. Observed Trends in Extreme Temperature over the Klang Valley, Malaysia. Adv. Atmos. Sci. 2019, 36, 1355-1370. [CrossRef] 
4. Coumou, D.; Rahmstorf, S. A Decade of Weather Extremes. Nat. Clim. Chang. 2012, 2, 491-496. [CrossRef]

5. Robine, J.-M.; Cheung, S.L.K.; Le Roy, S.; Van Oyen, H.; Griffiths, C.; Michel, J.-P.; Herrmann, F. Death Toll Exceeded 70,000 in Europe during the Summer of 2003. Comptes Rendus Biol. 2008, 331, 171-178. [CrossRef]

6. Cai, W.; Zhang, C.; Suen, H.P.; Ai, S.; Bai, Y.; Bao, J.; Chen, B.; Cheng, L.; Cui, X.; Dai, H.; et al. The 2020 Report of the Lancet Countdown on Health and Climate Change: Responding to Converging Crises. Lancet 2021, 397, 129-170. [CrossRef]

7. Zhang, G.; Zeng, G.; Liang, X.-Z.; Huang, C. Increasing heat risk in China's urban agglomerations. Environ. Res. Lett. 2021, 16, 064073. [CrossRef]

8. Sun, Y.; Zhang, X.; Zwiers, F.W.; Song, L.; Wan, H.; Hu, T.; Yin, H.; Ren, G. Rapid Increase in the Risk of Extreme Summer Heat in Eastern China. Nat. Clim. Chang. 2014, 4, 1082-1085. [CrossRef]

9. Chen, Y.; Hu, Q.; Yang, Y.; Qian, W. Anomaly Based Analysis of Extreme Heat Waves in Eastern China during 1981-2013. Int. J. Climatol. 2017, 37, 509-523. [CrossRef]

10. Wen, Q.H.; Zhang, X.; Xu, Y.; Wang, B. Detecting Human Influence on Extreme Temperatures in China. Geophys. Res. Lett. 2013, 40, 1171-1176. [CrossRef]

11. Ye, D.; Yin, J.; Chen, Z.; Zheng, Y.; Wu, R. Spatiotemporal Change Characteristics of Summer Heatwaves in China in 1961-2010. Clim. Chang. Res. 2013, 9, 15-20. [CrossRef]

12. Ding, T.; Qian, W.; Yan, Z. Changes in Hot Days and Heat Waves in China during 1961-2007. Int. J. Climatol. 2010, 30, 1452-1462. [CrossRef]

13. Wang, X.; Yan, Y.; Yue, S.; Liu, B. On spatiotemporal variations of heat waves in the Yangtze River Basin from 1961 to $2010 . J$. Yunnan Univ. 2016, 38, 602-609.

14. Chen, Y.; Zhang, L.; Qian, H. Variation Characteristics and Spatial Differences of Extremely High Temperature Days over South China during the Recent 53 Years. Trop. Geogr. 2016, 7, 692-699. [CrossRef]

15. Zhang, Z.; Wang, S.; Shang, K.; Chen, L.; Wang, H.; Yan, X.; Wang, M. Analysis of the atmospheric circulation anomalies of large-scale extreme high temperature events over central China in recent 50 years. J. Lanzhou Univ. Nat. Sci. 2011, 47, 50-55. [CrossRef]

16. Wang, W.; Zhou, W.; Wang, X.; Fong, S.K.; Leong, K.C. Summer high temperature extremes in Southeast China associated with the East Asian jet stream and circumglobal teleconnection. J. Geophys. Res. Atmos. 2013, 15, 8306-8319. [CrossRef]

17. Zhang, Y. Study on the Spatial Distribution and Atmospheric Circulation Cause of Extreme High Temperature over Eastern China in Summer. Master's Thesis, Lanzhou University, Lanzhou, China, 2015.

18. Luo, M.; Lau, N.-C. Heat Waves in Southern China: Synoptic Behavior, Long-Term Change, and Urbanization Effects. J. Clim. 2017, 30, 703-720. [CrossRef]

19. Chen, J.; Han, J.; Zhang, S.; Yan, F.; Yang, P. Study on forecast element of heat stroke weather grade based on hotness index in Hebei province. J. Meteorol. Environ. 2013, 29, 86-91.

20. Zheng, G. Study on Physiological Responses of Relative Population in Hot and Humid Environments. Ph.D. Thesis, Tianjin University, Tianjin, China, 2013.

21. Li, C. Effects of Relative Humidity and Its Dynamic Change on Human Thermal Comfort. Ph.D. Thesis, Chongqing University, Chongqing, China, 2018.

22. Tan, M. Effects of Air Humidity and Velocity on Human Thermal Sensation in Summer. Ph.D. Thesis, Chongqing University, Chongqing, China, 2012.

23. Tian, Y.; Xu, W. Experiment of human thermal response in warm and humid environment. Heat. Vent. Air Cond. 2003, 33, 27-30.

24. Ding, T.; Qian, W. Geographical Patterns and Temporal Variations of Regional Dry and Wet Heatwave Events in China during 1960-2008. Adv. Atmos. Sci. 2011, 28, 322-337. [CrossRef]

25. Chen, R.; Lu, R. Dry Tropical Nights and Wet Extreme Heat in Beijing: Atypical Configurations between High Temperature and Humidity. Mon. Weather Rev. 2014, 142, 1792-1802. [CrossRef]

26. Xu, F.; Chan, T.O.; Luo, M. Different changes in dry and humid heat waves over China. Int. J. Climatol. 2021, 41, 1369-1382. [CrossRef]

27. Kang, S.; Eltahir, E.A.B. North China Plain Threatened by Deadly Heatwaves Due to Climate Change and Irrigation. Nat. Commun. 2018, 9, 2894. [CrossRef]

28. Coffel, E.D.; Horton, R.M.; de Sherbinin, A. Temperature and Humidity Based Projections of a Rapid Rise in Global Heat Stress Exposure during the 21st Century. Environ. Res. Lett. 2017, 13, 014001. [CrossRef]

29. Raymond, C.; Matthews, T.; Horton, R.M. The Emergence of Heat and Humidity Too Severe for Human Tolerance. Sci. Adv. 2020, 6, eaaw1838. [CrossRef]

30. Russo, S.; Sillmann, J.; Sterl, A. Humid Heat Waves at Different Warming Levels. Sci. Rep. 2017, 7, 7477. [CrossRef] [PubMed]

31. $\mathrm{Xu}, \mathrm{W}$. Characteristic and Comfortability Evaluation of Two Types of Summer High Temperature Weather. Meteorol. Sci. Technol. 2014, 42, 719-724. [CrossRef]

32. Peng, H. Effect of Individual Differences on Physiological Responses under Hot-Dry and Hot-Humid Environment. Master's Thsis, Tianjin University, Tianjin, China, 2014.

33. Chen, X.; Li, N.; Huang, C.; Liu, J.; Zhang, Z. Projection of heatwaves by the combined impact of humidity and temperature in China. Prog. Geogr. 2020, 39, 36-44. [CrossRef] 
34. Wu, J.; Gao, X.J. A gridded daily observation dataset over China region and comparison with the other datasets. Chin. J. Geophys. 2013, 56, 1102-1111.

35. Kalnay, E.; Kanamitsu, M.; Kistler, R.; Collins, W.; Deaven, D.; Gandin, L.; Iredell, M.; Saha, S.; White, G.; Woollen, J.; et al. The NCEP/NCAR 40-Year Reanalysis Project. Bull. Am. Meteorol. Soc. 1996, 77, 437-471. [CrossRef]

36. Rothfusz, L.P. The Heat Index Equation (or, More than You Ever Wanted to Know about Heat Index); SR 90-23; National Oceanic and Atmospheric Administration, National Weather Service, Office of Meteorology: Fort Worth, TX, USA, 1990.

37. Gao, S. Applied Climatology; China Meteorological Press: Beijing, China, 2001.

38. Dang, B.; Liu, B.; Yin, L.; Zhou, Z.; He, S.; Li, T.; Shang, K.; Wang, S. Effect of meteorological conditions on heatstroke in summer and its prediction in Beijing. J. Meteorol. Environ. 2015, 31, 67-72.

39. He, X. Safety Engineering; China University of Mining and Technology Press: Xuzhou, China, 2000.

40. Nevins, R.; Gonzalez, R.; Nishi, Y.; Gagge, A.P. Effect of Changes in Ambient Temperature and Level of Humidity on Comfort and Thermal Sensations. ASHRAE Trans. 1975, 81, 64-77.

41. Plumb, R.A. On the Three-Dimensional Propagation of Stationary Waves. J. Atmos. Sci. 1985, 42, 217-229. [CrossRef]

42. Tan, G.; Sun, Z.; Lin, Z.; Jia, J. Land High over Area South to Lake Baikal and Its Relation with East Asian Summer Monsoon and Climate Anomalies of China. Clim. Environ. Res. 2008, 13, 791-799. [CrossRef]

43. Wang, L.; Chen, X.; Guan, Z.; Zeng, M. Relationships between the position variation of the west pacific subtropical high and the diabatic heating during persistent intense rain events in Yangtze-Huaihe rivers basin. J. Trop. Meteorol. 2012, 18, 528-536. [CrossRef]

44. Ye, T.; Zhi, R.; Zhao, J.; Gong, Z. The two annual northward jumps of the West Pacific Subtropical High and their relationship with summer rainfall in Eastern China under global warming. Chin. Phys. B 2014, 23, 660-669. [CrossRef]

45. Li, X. Study on the Extreme High Temperature Events in Summer and Its Effect in Recent 30 Years in North China. Master's Thesis, Lanzhou University, Lanzhou, China, 2015.

46. Sun, J.; Wang, H.; Yuan, W. Decadal variability of the extreme hot event in China and its association with atmospheric circulations. Clim. Environ. Res. 2011, 16, 199-208. [CrossRef]

47. Zhou, F.; Zhang, R.; Han, J. Relationship between the Circumglobal Teleconnection and Silk Road Pattern over Eurasian continent. Sci. Bull. 2019, 64, 374-376. [CrossRef]

48. Deng, K.; Yang, S.; Ting, M.; Lin, A.; Wang, Z. An intensified mode of variability modulating the summer heat waves in eastern Europe and northern China. Geophys. Res. Lett. 2018, 45, 11361-11369. [CrossRef]

49. Zhang, G.; Zeng, G.; Li, C.; Yang, X. Impact of PDO and AMO on interdecadal variability in extreme high temperatures in North China over the most recent 40-year period. Clim. Dyn. 2020, 54, 3003-3020. [CrossRef]

50. Li, J.; Zeng, G.; Yang, X.; Zhang, G. Classification of summer extreme high temperature events in Northeast China and their relationships with sea surface temperature anomalies in North Atlantic. Trans. Atmos. Sci. 2021, 44, 302-313. [CrossRef]

51. Ding, T.; Yuan, Y.; Gao, H.; Li, W. Impact of the North Atlantic sea surface temperature on the summer high temperature in northern China. Int. J. Climatol. 2020, 40, 2296-2309. [CrossRef]

52. Francis, J.A.; Vavrus, S.J. Evidence linking Arctic amplification to extreme weather in mid-latitudes. Geophys. Res. Lett. 2012, 39, L06801. [CrossRef]

53. Meng, L.; Shen, Y. On the Relationship of Soil Moisture and Extreme Temperatures in East China. Earth Interact. 2014, 18, 1-20. [CrossRef]

54. Wu, R.; Zeng, G.; Yang, X.; Zhang, G. Interdecadal variability of mid-summer high temperature days in northern China and its association with soil moisture in Mongolian plateau. Prog. Geophys. 2021, 36, 78-87. [CrossRef] 